\title{
A FORMAÇÃO DO PROFESSOR EM FOCO: O PAPEL DO ESTÁGIO
}

\author{
ERIK YUDI HORIYE (UEL/UNOPAR) ${ }^{1}$ \\ https://orcid.org/0000-0002-9305-2904
}

\author{
ANDREIA CUNHA MALHEIROS SANTANA (UEL) $)^{2}$ \\ https://orcid.org/0000-0002-3506-9716
}

\begin{abstract}
RESUMO: O presente artigo teve por objetivo central investigar as dificuldades encontradas durante a realização do estágio supervisionado nos cursos de licenciatura em Educação Física e LetrasPortuguês de uma universidade pública do estado do Paraná- Brasil, identificando os seus pontos positivos e negativos, bem como o contexto no qual ele está inserido. A fundamentação teórica articulou o discurso legal que regulamenta o estágio nos cursos de licenciatura, bem como as reflexões de diferentes estudiosos sobre a importância deste momento na formação do professor, a saber Pimenta e Lima (2006), Andrade e Resende (2010), França (2008), entre outros. O estágio foi analisado a partir da opinião dos estudantes do quarto ano dos cursos citados e dos seus supervisores de estágio, trata-se de um recorte de uma pesquisa descritiva qualitativa (Gamboa, 2012). As conclusões finais deste estudo apontam que os futuros professores reconhecem a importância desta etapa na sua formação docente, e que muitas dificuldades estão presentes nas duas licenciaturas, o que se deve ao fato de estarem inseridas na mesma conjuntura social, política e econômica, o maior desafio encontrado pelos estagiários de ambos os cursos é a aproximação das disciplinas durante o curso com a realidade escolar e da própria universidade com a escola.
\end{abstract}

PALAVRAS-CHAVE: Estágio Supervisionado. Educação Física. Letras-Português. Formação de Professores.

\section{THE TRAINING OF THE TEACHER IN FOCUS: THE ROLE OF THE INTERNSHIP}

\begin{abstract}
The objective of this paper was to investigate the difficulties encountered during the supervised internship in the undergraduate courses in Physical Education and Portuguese Letters of a public university in the state of Paraná, Brazil, highlighting its positive and negative aspects, as well as the context in which it is inserted. The theoretical foundation articulated the legal discourse that regulates the internship in undergraduate courses, as well as the reflections of different scholars (Pimenta, Lima, 2006; Andrade, Resende, 2010; França, 2008) regarding the importance of this moment in the teacher training. The internship was analyzed based on the opinion of the fourth year students and their trainee supervisors, it is a cut of a qualitative descriptive research (Gamboa, 2012). The final conclusions of this study indicate that, according to the voices of the research subjects, the reality in the two undergraduate degrees is close because they are inserted in the same social, political and economic context, the greatest challenge encountered by the trainees of both courses is the approximation of the disciplines studied during the course with the school reality, and of the university itself with the school.
\end{abstract}

KEYWORDS: Supervised Internship. Physical Education. Letters-Portuguese. Teacher Training

\footnotetext{
${ }^{1}$ Mestre em Educação pela Universidade Estadual de Londrina (UEL, 2018), pós-graduado lato sensu em Docência no Ensino Superior pela Faculdade São Braz (2020), graduado em Educação Física - Licenciatura pela Universidade Estadual de Londrina (UEL, 2015). Graduação em andamento em Engenharia Civil pela Universidade Norte do Paraná (UNOPAR). E-mail: erikyudi.uel@gmail.com

2 Docente da Universidade Estadual de Londrina. Doutora em Educação Escolar pela Universidade Estadual Paulista Júlio de Mesquita Filho. E-mail: andreiacunha@uel.br 


\section{$=$ TRAMA $=$}

\section{INTRODUÇÃO}

O papel do estágio no curso de formação de professores tem suscitado muitas questões tais como: que tipo de licenciando as instituições de ensino estão formando, o estágio tem sido o ponto articulador da formação docente? Segundo Pimenta e Lima (2006), o estágio possui uma concepção dualista em relação à teoria e à prática, evidenciando dois momentos distintos durante a graduação: os estudantes enquanto alunos e como professores. Alguns estudantes, futuros docentes, acabam por questionar a realização do estágio supervisionado, pois o consideram desnecessário para a sua formação.

O Estágio Supervisionado encontra-se inserido como parte prática dos cursos de formação de professores. Esta concepção de estágio é um assunto recorrente desde as Escolas Normais (em 1833) até hoje. Neste sentido, Pimenta e Lima (2006) apresentam um breve panorama de como o estágio (ou prática de ensino) aparecia dentro dos cursos de formação de professores. A fim de evidenciar a importância desta etapa na formação docente trazemos alguns dados sobre a construção desta área nos cursos de formação.

Nos anos 1930, a prática se fazia presente em diferentes modelos de currículo de acordo com a legislação de cada estado, havia a necessidade da prática no campo profissional e esta aparecia com diversas terminologias como didática, metodologia, metodologia geral, prática de ensino, entre outras nomenclaturas. Interessante é que em 1939, a partir do DecretoLei 1190/39 (BRASIL, 1939) cria-se a Faculdade Nacional de Filosofia, possibilitando que ao término do curso de bacharelado em Filosofia, o acadêmico pudesse cursar mais um ano de Didática para obter o título de licenciado, muitos outros cursos acabaram seguindo o mesmo padrão. Isso levou a uma dicotomia que, segundo Rodrigues (2011), existe até os dias atuais, mesmo após diversas mudanças legislativas, em relação às disciplinas teóricas e à prática do estágio.

A partir de 1964, após o golpe militar, adotou-se o modelo tecnicista, confirmado pela Lei 5692/71 (BRASIL, 1971) que alterou a estrutura da Escola Normal para $1^{\circ}$ e $2^{\circ} \mathrm{grau}$ profissionalizante. Segundo Rodrigues (2011), a habilitação profissionalizante passou a ter caráter terminal, com apenas 3 anos de curso, sendo os 2 últimos com disciplinas voltadas ao magistério e ainda somente no último ano aparecia a prática de ensino, o aluno já estaria habilitado para o magistério, desta forma a desvalorização do estágio tem uma perspectiva histórica, quer seja no ensino superior, quer no nível secundário.

Pimenta e Lima (2006) e Andrade e Resende (2010) chamam a atenção para o Parecer 349/72, no qual ressalta que a Didática fundamentaria a Metodologia de Ensino e este conduziria a Prática de Ensino sob a forma de estágio supervisionado de maneira que deverse-ia respeitar o embasamento teórico aprendido na Metodologia e Didática. se evidencia a Didática enquanto teoria e a Prática de Ensino sob a forma de Estágio enquanto prática. Para os autores, este parecer aponta para uma dissociação entre teoria (Didática) e prática (Prática de Ensino) além da ideia de que o estágio é a reprodução verdadeira e positiva do que é estudado na "teoria".

Nos anos de 1980, com a promulgação da Lei 7044/82 (Brasil, 1982), houve reivindicações por parte de educadores para o reconhecimento das escolas enquanto "instituições sociais cuja função específica é a produção e difusão do saber historicamente acumulado, como instrumentalização dos alunos para participação das lutas sociais mais amplas" (PIMENTA; LIMA 2006, p. 58).

Para as autoras, não reconhecer a escola como ambiente de formação também para o professor é um erro. É preciso que haja mais integração entre a universidade e as escolas da Educação Básica, sendo que alguns professores dos cursos de licenciatura não conhecem a 


\section{$=$ TRAMA $=$}

realidade do ensino básico, uma vez que não é exigido que o professor universitário tenha experiência na educação básica, nem tampouco que seja licenciado.

Neste sentido, seria vital ampliar o envolvimento e o interesse na realização do estágio supervisionado durante a formação inicial e que este acontecesse aglutinando às diferentes disciplinas (SANTANA; INFORSATO, 2011). Corroborando esta ideia, Fontana (2011, p. 20) aponta o estágio como "uma atividade intersubjetiva que envolve a proficiência, desconhecimentos e projetos de estagiários e de seus formadores, na universidade e na escola básica".

Ao discorrermos de forma breve sobre a historicidade do Estágio, podemos afirmar que a necessidade histórica é atender as demandas do mercado capital, que adentra na educação, desde a educação infantil até o ensino superior. O estágio supervisionado perde o real sentido na formação docente quando é atrelado à lógica de produção, ou seja, o estudante aplica na prática o que aprendeu na teoria, sem se importar com o contexto em que acontece o estágio.

Entendemos também que não se trata apenas da consciência do próprio estagiário, mas dos professores orientadores e colaboradores, dos coordenadores de estágio, do curso de licenciatura e do seu currículo, da universidade e da sua gestão e principalmente do Estado, este o maior responsável por acatar as demandas mercadológicas com implicações nas práticas educativas e, consequentemente, no estágio.

Neste sentido, pretendeu-se analisar a organização do estágio curricular obrigatório em dois cursos de licenciatura da Universidade Estadual de Londrina (UEL) e relacioná-la com a opinião dos estudantes sobre este momento de sua formação, com este intuito, este artigo está estruturado da seguinte forma: a primeira seção, intitulada "O Caminho Seguido", explica as opções metodológicas realizadas e os instrumentos utilizados (como o questionário e as entrevistas), justifica as escolhas feitas e indica a fundamentação teórica utilizada na metodologia. A segunda seção, "A realidade do estágio supervisionado em Educação Física e Letras-Português", promove a apresentação e discussão dos dados problematizando a relação entre teoria e prática, à luz da contribuição de autores da área, como Pimenta e Lima (2006), Cesário, Lugle, Carvalho, Czernisz e Fávaro (2013), Silva e Pereira (2016) e outros. Para finalizar o artigo, são apresentadas as considerações finais que apontam as semelhanças entre os cursos e as contradições existentes na formação docente, principalmente no que se refere à falta de diálogo entre o que é trabalhado na licenciatura e o que é exigido do docente na educação básica.

\section{O CAMINHO SEGUIDO}

O presente artigo é um recorte de uma pesquisa descritiva qualitativa. O estudo tinha como objetivo investigar, segundo a concepção dos licenciandos, quais os desafios e possibilidades encontrados durante a realização do Estágio Curricular Obrigatório nos cursos de licenciatura em Educação Física e Letras-Português da UEL.

A fim de centrar o nosso olhar para uma realidade concreta, optamos por selecionar dois cursos de licenciatura: Educação Física e Letras-Português. Esta escolha ocorreu por serem os cursos de formação dos autores deste artigo. Além disso, os dois cursos abordam diferentes formas de linguagens como a linguagem corporal na Educação Física e a linguagem discursiva em Letras, importantes para a comunicação, construção e leitura do mundo em que estamos inseridos.

Os estudantes do curso são os sujeitos em formação docente, que estão passando pela vivência do estágio. Por estarem em contato direto com a escola de educação básica e 


\section{$=\mathrm{T} R A M A=$}

com a universidade, contribuíram para a nossa pesquisa ao analisar essa relação entre Universidade-Escola. A fim de identificar as dificuldades encontradas durante o estágio de docência, foi elaborado um questionário, sendo 13 objetivas e 06 dissertativas. As respostas foram analisadas a partir do Software IBM SPSS Statistics versão 22.0 para a tabulação dos dados. Após o questionário, realizou-se uma entrevista parcialmente estruturada com o coordenador do estágio dos referidos cursos (GIL, 2002). A escolha pelos professores coordenadores de estágio se justifica pela função que eles exercem no estágio, além da orientação, atendem às questões burocráticas e organizacionais do mesmo. A partir da entrevista, relacionamos seus dizeres com as respostas dos estudantes, articulando as contradições existentes e as correlações dos sujeitos da pesquisa.

Durante a apresentação dos dados, os estudantes de Educação Física foram identificados como EF e os estudantes de Letras-Português como LP. Os coordenadores de estágio, identificados como CEF (coordenador Estágio Supervisionado em Educação Física) e CLP (Coodenador de Estágio Supervisionado em Letras-Português). Na próxima seção, os dados levantados serão apresentados e analisados.

\section{A REALIDADE DO ESTÁGIO SUPERVISIONADO EM EDUCAÇÃO FÍSICA E LETRAS- PORTUGUÊS}

Ao analisar a realidade do Estágio Supervisionado dos cursos de Educação Física e Letras-Português, percebemos diferentes questionamentos, alguns específicos das respectivas áreas de conhecimento, mas outros com bastante aproximação. Muitos pontos se aproximam devido à mesma legislação que rege todos os estágios, sendo que a realidade de sua cada organização acaba sendo bem parecida uma da outra. Assim, articulamos um diálogo entre as duas realidades analisadas, de modo que juntas, possam extrair possibilidades para minimizar os desafios encontrados por parte dos estudantes e dos coordenadores de estágio.

Sobre o perfil dos estudantes das referidas licenciaturas, foi possível observar que existe bastante aproximação. Nesse sentido, observou-se que, a maioria, dos futuros professores nos dois cursos, é do público feminino, do período noturno e com faixa etária entre 20 a 24 anos. Tal constatação confirma o que o Censo da Educação Superior (2016) que aponta: que essa predominância acontece na maioria das licenciaturas: " $71,1 \%$ das matrículas em cursos de licenciaturas no Brasil no ano de 2016 são do sexo feminino, enquanto 28,9\% são do sexo masculino". (MEC, 2016)

Gráfico 1 - Sexo

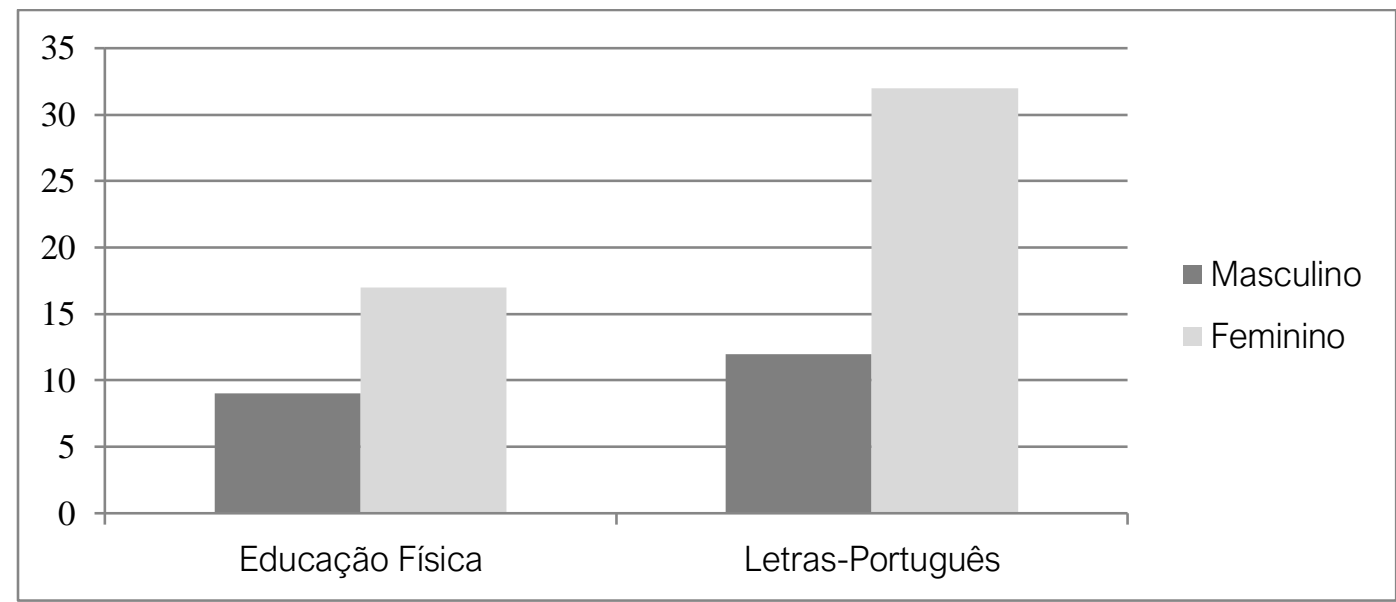

Fonte: Elaborado pelos autores (2018). 


\section{$=\mathrm{T} R A M A=$}

O Gráfico 2 demonstra a preferência dos estudantes pelo turno noturno em ambos os cursos. Ainda segundo o Censo da Educação Superior (MEC, 2016) 60,6\% das matrículas relativas aos cursos de graduação no Brasil foram no período noturno, apontando para uma preferência por este turno. Nesse sentido, os dados levantados nesta pesquisa comprovam esta tendência. Vivemos em uma sociedade marcada pelo consumo, globalização e competitividade na qual se exige que o estudante trabalhe para o sustento e estude para melhor qualificação. Dessa forma, Terribili Filho (2008) relaciona a preferência por estudar à noite com a possibilidade de trabalhar durante o dia a fim de buscar recursos financeiros para o sustento da família, para o próprio sustento, bem como recursos para arcar com as despesas com os estudos, entre outras necessidades.

Gráfico 2 - Turno

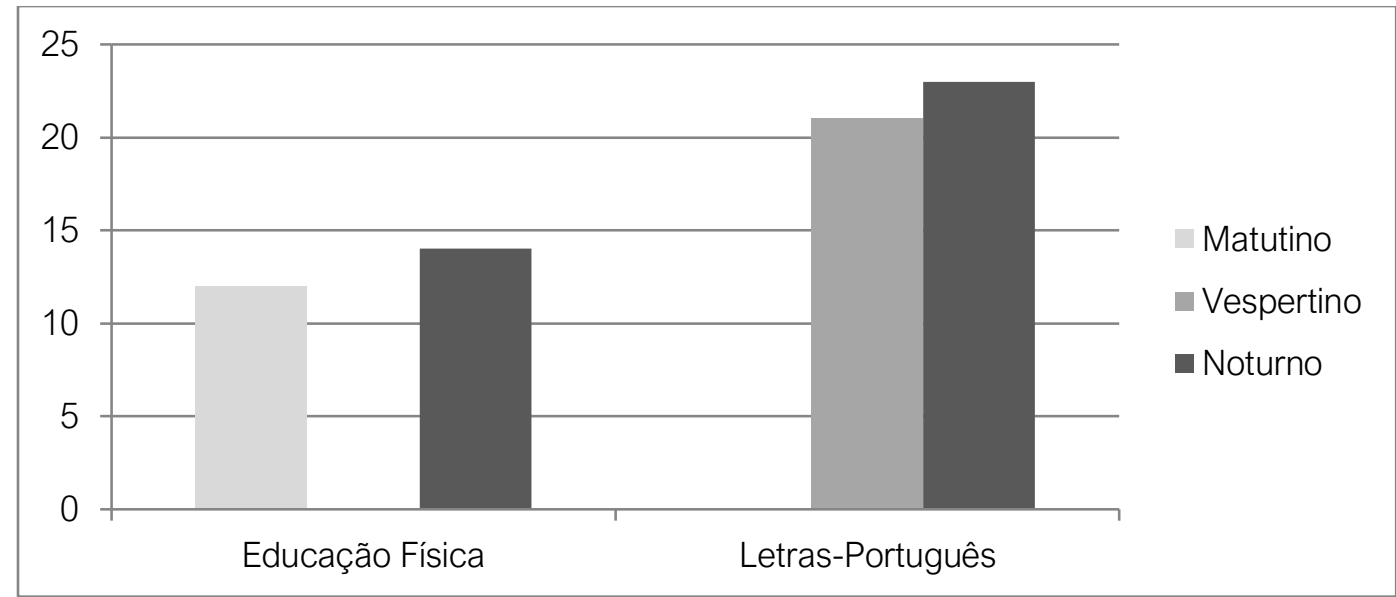

Fonte: Elaborado pelos autores (2018).

Um dos pontos em comum nos dois cursos foi a valorização do Estágio Supervisionado para os estudantes. Quando questionados se consideram o Estágio importante para a formação inicial de professores, a maioria dos estudantes considera bastante importante, sendo que em Educação Física apenas um considera pouco importante e em Letras-Português, apenas 5 considera razoável, conforme é possível observar no gráfico que segue.

Gráfico 3 - Considera o Estágio Supervisionado importante para a formação inicial de professores?

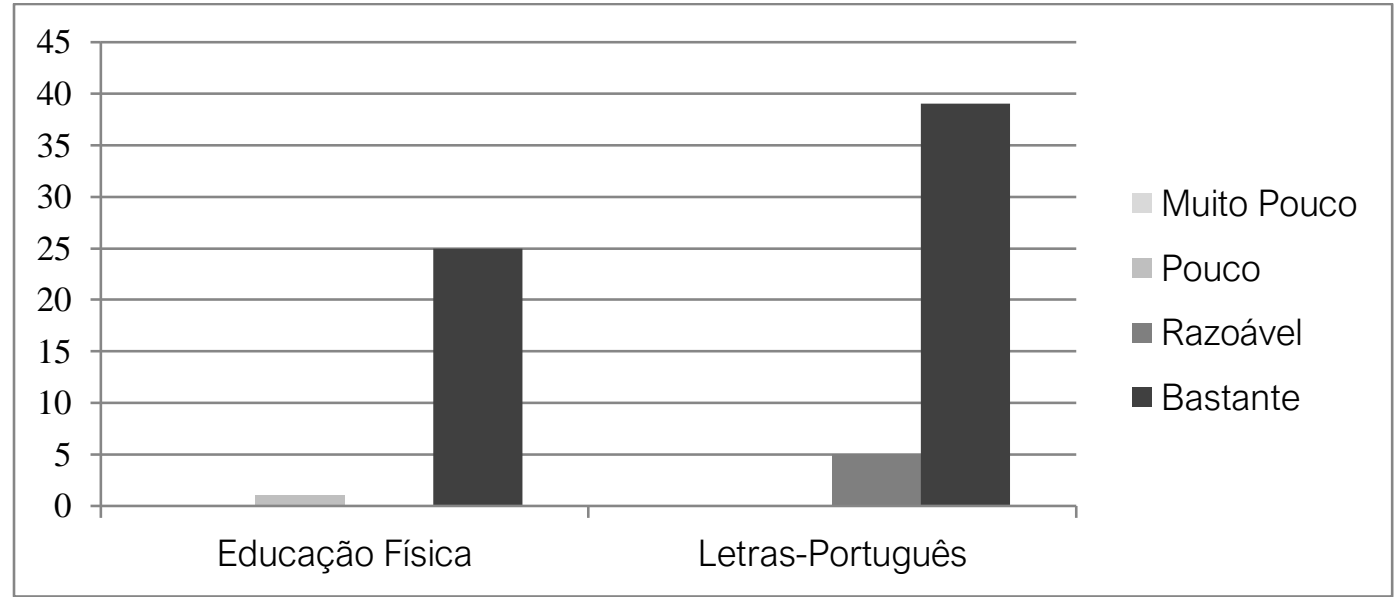

Fonte: Elaborado pelos autores (2018). 


\title{
$=$ TRAMA $=$
}

Sobre a importância do Estágio Supervisionado, os estudantes de ambos os cursos afirmam praticamente a mesma coisa. A maioria dos educandos entende que o estágio é importante, pois permite a vivência da realidade escolar, da docência e o cotidiano da futura profissão.

\begin{abstract}
Considero muito importante, porque é nesses estágios que conseguimos ver realmente como é a rotina da escola, além de poder vivenciar o momento de ministrar aula, é no estágio que percebemos se o plano de aula foi adequado ou não, nos mostra o que precisa melhorar (EF 2).

Por se tratar da maior oportunidade de contato com o ambiente e as práticas de trabalho do professor em formação (LP 26).
\end{abstract}

Além de o estágio permitir a vivência da realidade escolar, os discursos indicam que é o momento decisivo da profissão docente

Acredito que é o ponto chave para seguir na profissão e assim preparar para o futuro (EF 21).

É importante para decidirmos se for optar pela profissão (LP 11).

Nota-se que nestes casos, recai sobre o Estágio Supervisionado o fator decisivo do futuro do estudante, sendo que a escolha de ser professor deve ser formada durante todo o curso. Isso ocorre porque muitas vezes é somente no Estágio que o educando tem a possibilidade de vivenciar de fato a realidade da profissão.

Para os estagiários de ambos os cursos, o estágio também é o momento de aplicar na prática o que se aprende na teoria. Deixa-nos evidente que prevalece ainda a dicotomia entre teoria e prática.

Um momento em que se coloca em prática o que se estuda ao longo do curso (EF 24).

Seria o momento em que eu poderia por em prática os conhecimentos adquiridos durante o curso de licenciatura, além de me proporcionar o contato e o aprendizado com a docência (LP 7).

Pimenta e Lima (2006) ressaltam ainda que a formação de professores imbuídos de consciência política e compromisso social aponta para uma concepção de prática na qual ela é indissociável da teoria. Rodrigues (2011, p. 23) ainda aponta que anos depois "as proposições estabelecidas pela LDB/96 sugeriram uma série de regulamentações, como por exemplo, o Parecer CNE/CP n²8/2001"3. Tal documento determina o mínimo de 400 horas para a realização do Estágio Supervisionado no curso de formação, indicando assim, uma visão que passou aparentemente a valorizar esse momento na formação docente. Entretanto a indissociabilidade entre prática e teoria ainda é um sonho e não uma realidade.

Segundo Cesário, Lugle, Carvalho, Czernisz e Fávaro (2013) um dos maiores desafios nos cursos de licenciaturas a ser superado é a instrumentalização do Estágio Supervisionado, ou seja, a ideia de que o estágio é apenas o momento de aplicar as técnicas "aprendidas" durante as disciplinas ditas "teóricas" sem entender a o estágio como eixo integrador dos diferentes conhecimentos e saberes que envolvem um curso de formação de professores. Esta dicotomia ainda existente entre teoria e prática é percebida nos discursos dos estudantes e

\footnotetext{
3 Para mais informações, consultar: BRASIL. Resolução CNE/CP 9, de 8 de maio de 2001 (2001). Institui Diretrizes Curriculares Nacionais para a Formação de Professores da Educação Básica, em nível superior, Curso de Licenciatura, de graduação plena. Brasília, 2001. Fonte: http://portal.mec.gov.br/cne/arquivos/pdf/009.pdf Acesso 26 nov. 2020
} 


\title{
$=$ TRAMA $=$
}

também na legislação, remetendo o Estágio Supervisionado a outra dimensão no curso de formação, o que comprova que a indissociabilidade entre teoria e prática ainda não é real. Segundo França (2008), mesmo que a teoria e prática sejam fundamentais para o processo de formação profissional, no estágio apresenta-se de maneira dissociada,

Tendo em vista que o estágio compreendido como uma prática meramente burocrática, visando apenas o cumprimento de tarefas, como a integralização da carga horária e, assim sendo é efetuado de forma pontual, servindo apenas para a mera descrição dos fatos, que pouco tem auxiliado o futuro professor em sua vivência no âmbito escolar (FRANÇA, 2008, p.37).

Sobre essa questão, analisamos que os discursos apontam para o Estágio configurado como atividade prática do que se aprende na universidade, indicando pouca vivência da realidade escolar e distanciamento das disciplinas do curso com a realidade da profissão. Pimenta e Lima ressaltam que

O estágio é um componente do currículo que não se configura como uma disciplina, mas como uma atividade. [...] o estágio pode servir às demais disciplinas e, nesse sentido, ser uma atividade articuladora do curso. [...] é uma atividade teórica (de conhecimento e estabelecimento de finalidades) na formação do professor. Instrumentalizadora da práxis (atividade teórico e prática) educacional. De transformação da realidade existente (PIMENTA; LIMA, 2006, p. 121).

Da mesma forma, os coordenadores também apontam para a questão da teoria e prática no Estágio:

\begin{abstract}
antes a gente tinha né... essa questão de práticas de ensino, aí as pessoas ficavam pensando no estágio: Ai, o estágio é a prática do que se aprendeu da teoria na universidade. A gente tenta lutar pra que isso não... não tenha essa perspectiva no nosso curso [...] A ideia é que a atividade de estágio, ela é mais uma etapa de aproximação da teoria com a prática né. Então na nossa perspectiva, o papel dela é de aproximação, numa práxis né, na aproximação na realidade do cotidiano que esse aluno nosso em formação ele vai ter (CEF).

Porque um dos conflitos que eu entendo dentro da formação de professores está vinculado a isso, ou seja, você trabalha um curso de formação de professores em que essas... diferentes atores, conteúdos e disciplinas, etc é... eles acabam se constituindo em chamados campos de teorias e campos de práticas que não dialogam. Então fortalecer o estágio, é... como você perguntou, dar visibilidade, mas visibilidade responsável e acadêmica para a atuação do estágio, eu acho que é um,... acaba ajudando a fortalecer essa maior integração teoria e prática e por extensão qualificando um curso de licenciatura (CLP)
\end{abstract}

É importante ressaltar que há no discurso do CLP, a compreensão da articulação teoria e prática por cada pessoa que faz parte desse processo de formação, professores e graduandos. Ambos precisam entender que o estágio se constitui como componente curricular, de modo a possibilitar a articulação e aproximação dos conhecimentos aprendidos durante a graduação e a realidade escolar, ou ainda como define Silva e Pereira (2016, p.152), "funcionam como espécies de nexos entre as demais disciplinas da matriz curricular".

O Estágio Curricular Obrigatório não é o momento apenas prático, e muito menos apenas teórico, mas "práxico". Segundo Vasquez (1977, p.185) "toda práxis é atividade, mas nem toda atividade é práxis". Nem toda prática de estágio é "práxica". O homem materializa sua atividade a partir da sua consciência, resultando assim no ideal e em seguida o real. A atividade é somente práxis quando é produto de sua consciência e se desenvolve de acordo com as finalidades. Neste mesmo caminho, Kosik (1976, p.222) complementa que a práxis não 


\section{$=$ TRAMA $=$}

é "atividade prática contraposta à teoria", mas "determinação da existência humana como elaboração da realidade". Assim, é a atividade que é produzida historicamente, ou seja, que sempre se renova. Já para Konder (1992, p.115), a práxis é a "atividade concreta pela qual os sujeitos humanos se afirmam no mundo", é uma ação que "precisa da reflexão, do autoquestionamento, da teoria; e é a teoria que remete à ação, que enfrenta o desafio de verificar seus acertos e desacertos".

A teoria se faz eficaz somente em conjunto com a prática, de modo que é nela que se afirma e fundamenta-se a verdade. Somente com a teoria, não é possível transformar a realidade. Sua finalidade, segundo Vásquez (1977) é transformar na dimensão ideal apenas, necessitando assim, o lado material (prática). De uma forma simples, Gamboa (2012) exemplifica o que é a práxis, entendendo a "teoria como teoria de uma prática e vice-versa, a prática sempre é prática de uma teoria. A teoria é entendida como a compreensão da prática". A práxis torna-se presente quando a prática do estágio, refere-se a uma atividade livre, criativa e auto criativa, no sentido do estagiário transformar a sua realidade histórica e a si mesmo. Observar o estágio apenas para anotar e criticar a prática do professor colaborador é uma prática puramente técnica e instrumental. Da mesma forma que reger uma aula apenas com o intuito de cumprir o plano de aula, às vezes não formulado pelo próprio estagiário, sem pensar em transformações da realidade presente também é uma prática técnica e instrumental, com fim nela mesma.

O CLP entende que a maior dificuldade que os estudantes encontram na realização do estágio é a desarticulação entre a teoria e a prática.

Olha, é.. eu acho que a dificuldade maior do estágio (...) é a desarticulação entre a teoria e a prática ao longo do curso né. Então repito, o aluno continua chegando no estágio como se fosse uma outra coisa que ele vai fazer quando na verdade se fosse, trabalhasse de forma integrada, essa ... experiência no campo de estágio seria algo menos traumático, eu digo traumático nesse sentido né, não é que nem sofre, mas é traumático porque a pessoa, é o momento em que ela olha para o curso dela e diz: o que que meu curso tem a oferecer para mim enquanto futuro profissional da educação entendeu... então eu acho que a maior dificuldade é essa... esse choque que acaba tendo da teoria com a prática, e aí.. então essa é uma questão (CLP).

No que diz respeito ao ensino de línguas, Silva e Pereira (2016) defendem a mesma ideia, é necessário que as disciplinas "teóricas" sejam desenvolvidas em função do ensino ao invés de servir de instrumento que "impulsionam discussões sobre o estruturalismo da língua" (p. 157). Entendendo dessa maneira, as disciplinas do curso permitirão que os estudantes façam as relações entre os saberes aprendidos e a realidade escolar. Um curso de licenciatura necessita a todo o momento articular o conhecimento estudado com a realidade escolar, afinal, o objetivo final é formar professores que estarão atuando na escola. Assim, percebe-se que é recorrente a questão da teoria e prática nos cursos de formação de professores, especificamente no Estágio Supervisionado.

Quando se tratou da aproximação da realidade escolar com o que era discutido nas disciplinas, percebemos pelos discursos dos estudantes que a realidade do estágio se aproxima razoavelmente do que é discutido nas disciplinas dos cursos em questão. Apresentamos abaixo duas questões referentes a essa aproximação, sendo à prática docente e às metodologias de ensino. 


\section{$=$ TRAMA $=$}

Gráfico 4 - A realidade do Estágio Supervisionado se aproxima do que é discutida em outras disciplinas em relação: À Prática Docente?

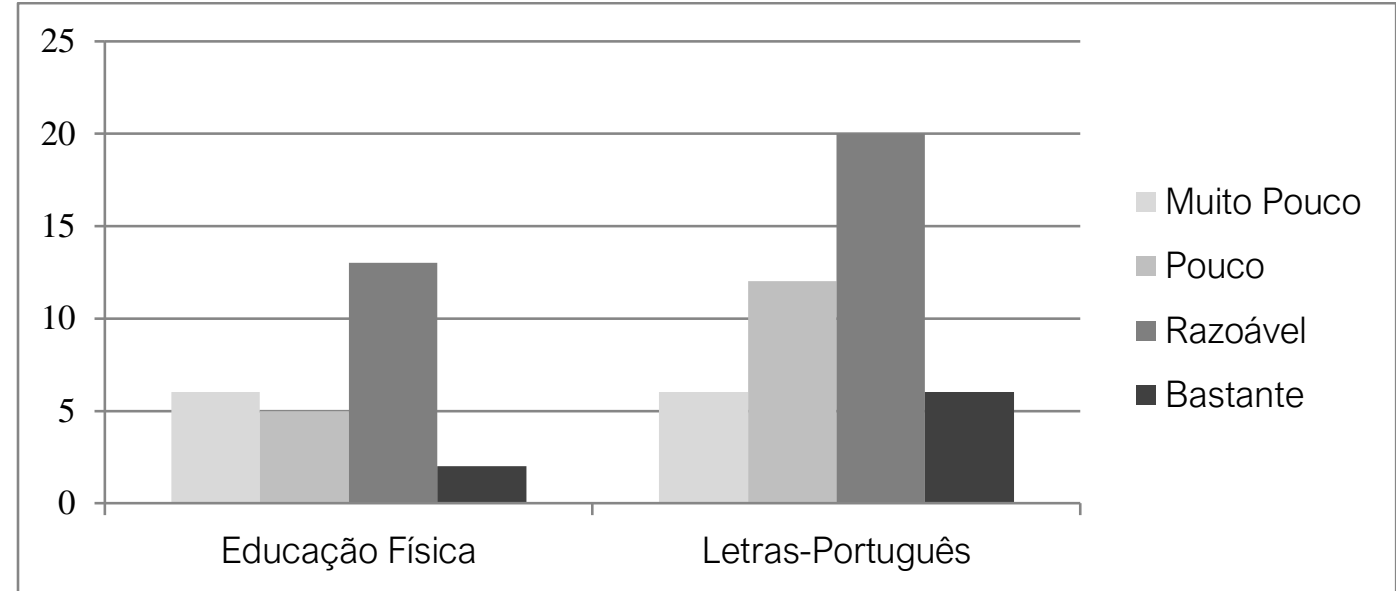

Fonte: Elaborado pelos autores (2018).

Em se tratando da relação entre o que é discutido nas disciplinas do curso e a realidade do Estágio Supervisionado sobre a prática docente, percebe-se que a maioria dos estudantes apontou uma razoável aproximação seguida de "pouca" e "muito pouca".

Aqui é possível visualizar uma preocupação maior com a questão da prática docente. De um modo geral, analisamos que nos dois cursos, as realidades são próximas, o que nos leva a repensar duas situações: 1) falta de articulação por parte do professor sobre a sua disciplina e a realidade escolar referente à prática docente; ou 2) falta de articulação por parte do estudante sobre o que é discutido na disciplina com a realidade escolar. Para essa discussão, temos as vozes dos estudantes, que nos forneceram uma ideia das dificuldades encontradas e guiaram a elaboração do roteiro para a entrevista com os professores supervisores:

Na realização das aulas, o curso não prepara para o que vamos encontrar na prática (EF 19).

Deparar-se com uma realidade bem diferente da teoria, a qual é mais trabalhada durante o curso em detrimento da prática (LP 25).

Torna-se um desafio desvendar por parte de quem o distanciamento acontece. Dessa forma, é essencial que o conhecimento ensinado aos estudantes seja articulado com a realidade escolar e se possível, aproximando-o da realidade a partir de vivências nas escolas antes do momento do estágio. Como explicita Ananias (2016, p. 178), é necessário que haja maior contextualização por parte dos professores "para que as disciplinas do curso que subsidiam efetivamente a prática docente sejam eficientes no suporte gradativo à inserção de futuros docentes nas escolas de Educação Básica". Ainda, Silva e Pereira (2016) enfatizam que a universidade necessita atender a demanda da educação básica tendo em vista a formação de um professor que saiba atuar na realidade presente da escola.

Considerando o exposto, destaca-se a importância de que todos os professores do curso de licenciatura conheçam a realidade escolar, para que as disciplinas na universidade não se encontrem distantes nem que sejam "terra de ninguém", como diz um dos estudantes. Por parte do estudante, está a tarefa de articular o conhecimento aprendido no momento da prática docente. Vale ressaltar que conforme afirma Téo (2012), a educação e a docência, a realidade da escola é marcada principalmente pela imprevisibilidade. Sendo assim, nem sempre o que é discutido na disciplina aponta de fato ao que acontecerá durante a aula.

Em se tratando de questões referentes à prática docente, analisamos também qual a percepção dos estudantes sobre aproximação da realidade no Estágio Supervisionado com o Revista Trama | Volume 17 | Número 41 | Ano 2021 | p. 45-58 | e-ISSN 1981-4674 


\section{$=\mathrm{T} R A M A=$}

que é discutido nas disciplinas do curso em relação às metodologias de ensino. Nesta questão, analisamos que a maioria dos estudantes consideram que há razoável e pouca aproximação.

Gráfico 5 - A realidade do Estágio Supervisionado se aproxima do que é discutida em outras disciplinas em relação: às Metodologias de Ensino?

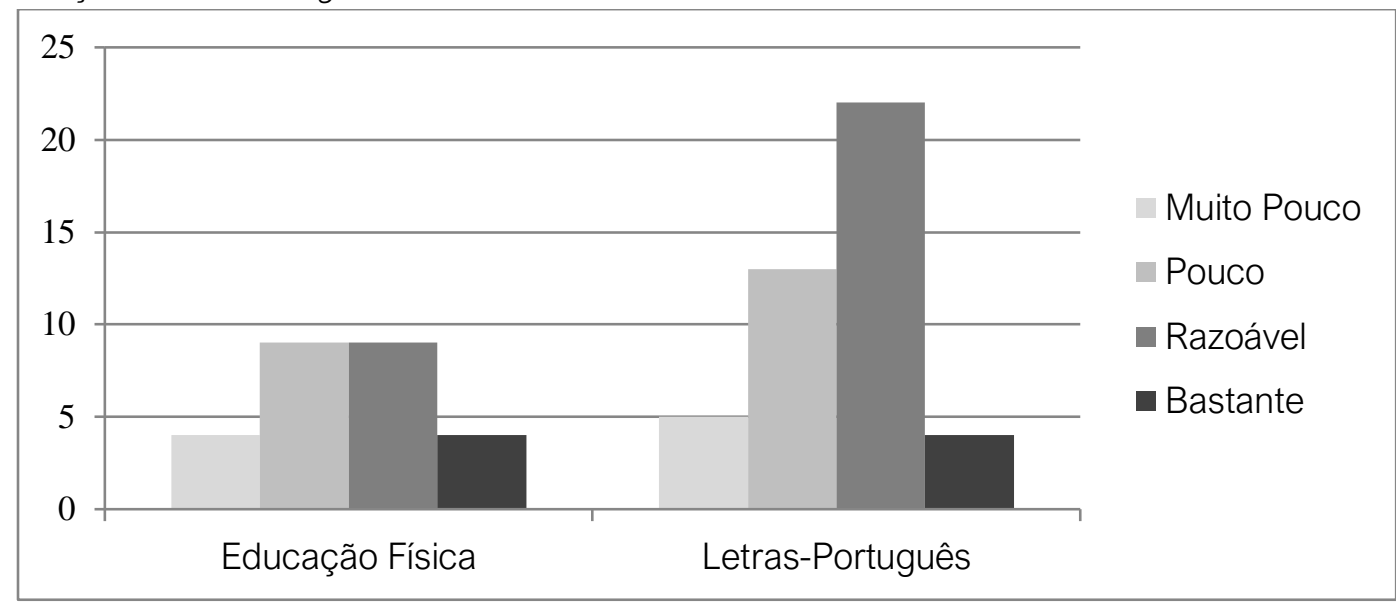

Fonte: Elaborado pelos autores (2018).

Analisando os discursos dos estudantes, em Educação Física apenas dois apontaram a dificuldade com a questão metodológica de ensino, sendo que em Letras-Português, sete estudantes destacaram esse ponto. Sobre os estudantes de Letras, é interessante notarmos que as maiores queixas indicam a dificuldade para manter a disciplina e a atenção dos alunos em sala de aula, apontamento que não ocorre na Educação Física. Segue abaixo alguns trechos dos discursos:

Na verdade, essa sugestão vai para além da organização do estágio e seria voltada para a organização do currículo e das disciplinas metodológicas, que acredito que deveriam fornecer um embasamento metodológico prático mais adequado e preceder o desenvolvimento do estágio (EF1).

[...] manter a turma em silêncio [...] (LP 10).

Disciplinas os alunos "bagunceiros" [...] (LP 2).

Sobre a questão da indisciplina, o CLP diz que

É o que eles costumam chamar de domínio de sala né, ou seja, essa questão, o que a gente sempre tem colocado para os alunos, nesse sentido, é observar, é aproveitar melhor o próprio período de observação. (...) mas quando você vai pra dentro de sala de aula e você leva um trabalho bem planejado e bem planificado, fica difícil o aluno, na pior das hipóteses respeitar você como um profissional em formação. Eu acho que isso não resolve, mas ajuda um pouco essa questão da disciplina (CLP)

Interessante que no curso de Educação Física, nenhum estudante se queixou de indisciplina por parte dos alunos da escola. Levamos em consideração a percepção social e histórica da disciplina de Educação Física, compreendida por momento de lazer, prática esportiva, diversão e para aqueles que não se interessam é o momento livre. Na disciplina de Língua Portuguesa, percebemos que o desafio da docência se encontra em despertar 0 interesse do estudante para a disciplina em si. Azevedo (2012) aponta a importância do professor de português contextualizar o conhecimento a ser ensinado: 


\section{$=$ TRAMA $=$}

O professor ressente-se ao observar o desempenho insatisfatório do alunado nas atividades que envolvem a leitura, a oralidade e a escrita, bem como constata o desinteresse e o desestímulo no aprendizado da língua, os quais, muitas vezes, geram a tão indesejável indisciplina, pois um ensino dissociado dos contextos de uso provoca a sensação de algo sem vida, sem aplicabilidade na vida prática, tornando-se tedioso e desenxabido (AZEVEDO, 2012, p. 91).

Neste mesmo caminho, o CLP também evidencia a importância de um bom planejamento antes da aula, para que envolva o estudante e mostre a relevância do conteúdo para a sua formação, o que é um desafio diante de uma sociedade que se diz "autônoma" (que buscam o seu próprio conhecimento ao invés do conhecimento historicamente construído ensinado no contexto escolar). Mas para um bom planejamento, é necessário o apoio de ambos os professores, supervisor e regente. Uma alternativa para o estagiário estar melhor preparado na questão da indisciplina do aluno seria uma matéria no curso que discutisse essa questão ou nas próprias disciplinas que tratassem de metodologia de ensino.

Ainda no curso de Letras-Português, alguns estudantes apontaram a necessidade de uma atualização por parte dos professores das metodologias de ensino estudadas nas aulas reforçando aqui o distanciamento entre a universidade e escola. Esse distanciamento ocorre às vezes por parte da universidade, quando os professores não buscam ver como está a realidade escolar, também por parte dos estudantes, que chegam à escola como avaliadores do ensino do professor regente e também por parte da escola, que não quer alterar o cotidiano só por causa de um estagiário.

Fontana (2011) explica que o estagiário, ao chegar na escola, é um estranho em um local desconhecido, permeado de individualidades.

O papel de estagiário não se enquadra nos papéis sociais que compõem a escola. Os estagiários não são alunos na escola em que estagiam, tampouco são professores, diretores ou funcionários dessa escola, nem alguém ligado às famílias daqueles que ali estudam. As pessoas reunidas na escola vivem o seu cotidiano, vivem a produção coletiva de significados, situam-se dentro dela. O estagiário não. Sua relação com a escola é uma relação deliberada de conhecimento. Sua ida à escola é precedida e acompanhada por leituras, conversas, orientações e reflexões. O estagiário sabe que se espera dele a discrição do que se vive e se produz na escola (FONTANA, 2011, p. 26).

É um grande desafio para o estudante chegar ao estágio e apresentar novas metodologias, propostas e conteúdos. Por isso, deve haver uma parceria, além da orientação do professor da universidade, com o professor regente, aquele que está presente no cotidiano dos alunos na escola. Somando-se ao exposto, sabemos que há certa resistência à aceitação da metodologia de ensino do estagiário pelos estudantes, pois sabem que ficarão por tempo determinado.

França (2008) chama a atenção para a responsabilidade do professor de não permitir que o conhecimento apreendido durante a graduação se perca no momento do estágio supervisionado. Segundo as vozes dos estudantes, alguns se queixaram do distanciamento que existe entre o que a universidade propõe e a realidade do Estágio Supervisionado.

A universidade, em específico as disciplinas, ou grande parte delas, está bem distante da escola, e quando nos encontramos em situação de estágio nos sentimos perdidos (EF 18). 
Dessa maneira o estudante usa o estágio de parâmetro para decidir se será ou não professor. Uma vez que há o distanciamento entre as duas instâncias formadoras, a desconfiança da presença do estagiário e o estudo de uma realidade que na verdade é outra. Em ambas as licenciaturas, o estágio foi o momento decisivo para a escolha da profissão. Enquanto as disciplinas pouco contemplarem a possibilidade de vivência escolar durante o curso, o Estágio Supervisionado será o principal momento de exercer a docência na realidade escolar e recairá a responsabilidade de ser o ponto crucial e decisivo na escolha de seguir a profissão. Realidades que se aproximam também na relação entre o estudante e o professor orientador. Ambos os cursos apontam positivamente para a contribuição do professor para o desenvolvimento do estágio.

Gráfico 6 - Você acha que o seu orientador contribuiu para o seu Estágio?

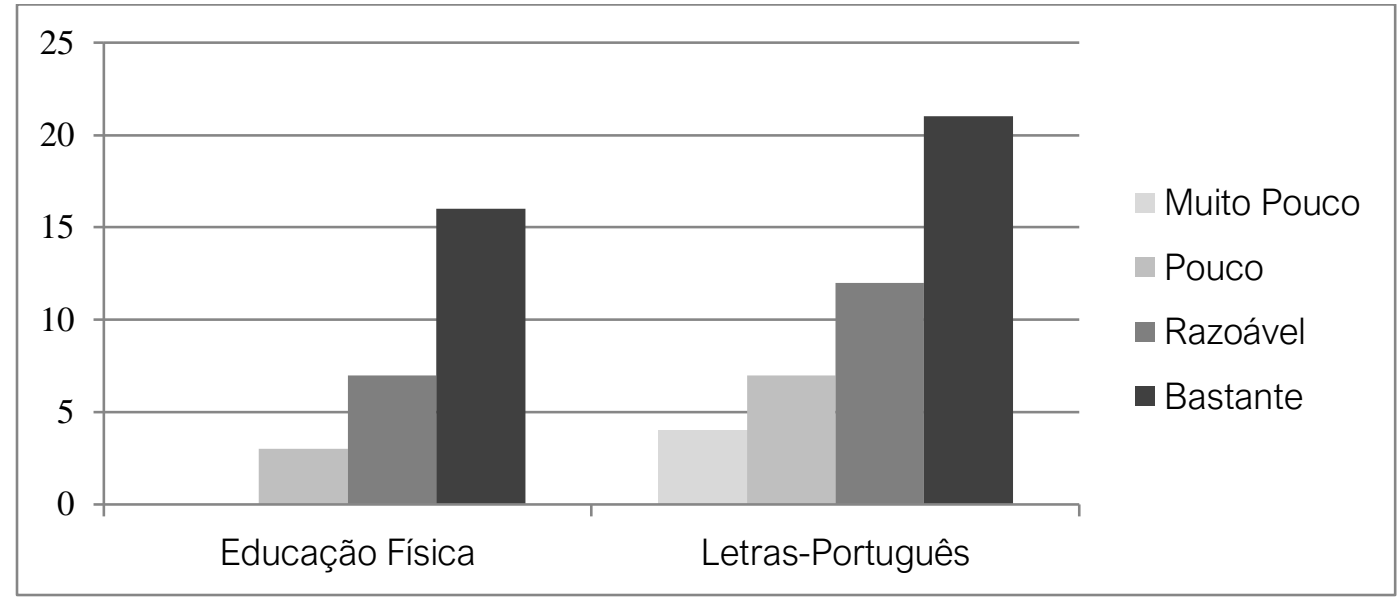

Fonte: Elaborado pelos autores (2018).

O orientador de estágio tem um papel fundamental na formação do estudante no momento do estágio supervisionado. É o professor que orienta no planejamento das aulas, nos questionamentos levantados pelos estudantes durante as observações e regências, auxilia o estagiário na articulação da prática docente no estágio com os conhecimentos das disciplinas estudadas no curso, é um participante ativo junto ao estagiário

Somente em situações pontuais houve contratempos entre o aluno e seu supervisor, por falta de orientação. O curso de Letras- Português até a realização da pesquisa não tinha um espaço no currículo para que os estudantes pudessem conversar com os professores orientadores. Desta forma, as orientações eram marcadas de acordo com a disponibilidade dos estudantes, o que dificultava um momento de troca de experiências entre todos os estagiários, pois a fim de viabilizar a presença dos estudantes nestes encontros de orientação, optava-se por por pequenas reuniões em dupla. No curso de Educação Física, a realidade era diferente, há um espaço na grade curricular destinado à orientação do estágio.

\section{CONSIDERAÇÕES FINAIS}

Através dos dados coletados, foi possível perceber que o estágio supervisionado se faz presente em um contexto permeado pela lógica capitalista e este influencia as políticas públicas educacionais. Atendendo às demandas do mercado, exige-se dos currículos da Educação Básica a construção de currículos pautados na aquisição das competências que acaba por formar um aluno com determinadas habilidades, cooperativo e capacitado para o trabalho. 


\section{$=$ TRAMA $=$}

Essa demanda do mercado de trabalho também atinge os cursos de formação de professores de modo que o estudante, quando não percebe a conjuntura social, econômica e política, encara o estágio supervisionado como forma de testar o que aprendeu nas disciplinas do curso, como um fardo para receber o "canudo", pois necessita do título da graduação para melhor qualificação no mercado de trabalho. O futuro professor só compreenderá o momento do estágio como forma de articular os conhecimentos aprendidos e necessários para a formação docente quando enxergar as contradições existentes na educação e na sociedade. Contradições que nos fazem repensar sobre nossas escolhas e ações diante da responsabilidade de ensinar os conteúdos construídos historicamente e de contribuir na formação dos estudantes nas escolas de Educação Básica.

Segundo as vozes dos estudantes, percebemos as contradições existentes na formação docente, quando a expectativa do aluno ao aprender os saberes nas disciplinas do curso é uma e ao encarar a realidade escolar é outra, totalmente diferente do que viu na universidade. Percebemos aqui a distância que ainda ocorre na formação, entre a universidade e a escola, entre o professor orientador e o professor regente. Vimos que o contexto social influencia as disciplinas da formação docente, os saberes que fazem parte de cada componente curricular. Assim, não cabe a culpa por parte do professor regente, como analisamos nos discursos dos estudantes, mas a implicação das políticas públicas educacionais.

Os maiores desafios que os estudantes encontraram referem-se às metodologias de ensino (tanto na universidade quanto nas escolas) o choque de realidade encontrado nas escolas, distanciamento entre as duas instâncias formadoras, dicotomização entre teoria e prática e algumas observações quanto ao professor orientador e professor regente. Os dados mostram que independente das especificidades de cada curso estudado nesta pesquisa, as realidades se aproximam.

Essa aproximação acontece principalmente por estarem situados no mesmo contexto. Como os cursos estão inseridos na mesma conjuntura política, social, econômica e cultural, as realidades acabam se aproximando. Em geral, os que mais sentem essa desvalorização não são os estagiários, futuros professores, ou os cursos de formação, mas são as crianças, que estão inseridas na Escola Pública, local onde o estagiário encara o estágio, são as camadas populares desfavorecidas e esquecidas, conhecidas, ironicamente como "futuro da nação".

Ao concluir este estudo, é possível salientar a falta de ouvir a voz do professor regente, sem ele não foi possível completar a tríade que envolve o estágio, por isso, ao terminar a pesquisa afirmamos que não chegamos a explorar o problema e que a solução ainda dependerá de uma série de fatores, entre eles a realização de pesquisas na área que podem também aproximar os estudantes da realidade educacional brasileira. Assim, como explicita Konder (2000) esperamos que este estudo intranquilize os comodistas, assuste os preconceituosos e perturbe desagradavelmente os pragmáticos ou utilitários, uma vez que este assunto não está esgotado, é preciso que as licenciaturas estejam refletindo a todo momento sobre a formação que estão oferecendo, sobre o quanto estão articulando a teoria e a prática e como o diálogo entre a universidade e a educação básica está acontecendo.

\section{REFERÊNCIAS}

ANANIAS, E. V. O estágio curricular supervisionado em educação física e o processo de profissionalização do ensino: um estudo de casos múltiplos. 2016. 213f. Tese (Doutorado em Ciência da Motricidade) Universidade Estadual Paulista, UNESP, Rio Claro, SP.

ANDRADE, R. C. R; RESENDE, M. R. Aspectos legais do estágio na formação de professores: uma retrospectiva histórica. Educação em perspectiva. Viçosa, MG, v. 1, n. 2, p. 230-252, jul./dez. 2010. Disponível em: http://www.seer.ufv.br/seer/educacaoemperspectiva/index.php/ppgeufv/article/view/77/35. Acesso em: 25 nov. 2020 


\section{$=\mathrm{T} R A M A=$}

AZEVEDO, J. A. M. Ensino de Língua Portuguesa: da formação do professor à sala de aula. 2012. 260f. Tese de doutorado, Universidade Federal do Rio Grande do Norte, Natal, RN, Brasil.

BRASIL. Decreto-Lei n 1.190/1939, 04 de abril de 1939. Dá organização à Faculdade Nacional de Filosofia. Brasília. 1939. Disponível em: http://www2.camara.leg.br/legin/fed/declei/1930-1939/decreto-lei-1190-4-abril1939-349241-publicacaooriginal-1-pe.html Acesso em: 25 nov. 2020

BRASIL. Lei $n^{\circ}$ 5.692/71 de 11 de agosto de 1971. Fixa diretrizes e bases o ensino de $1^{\circ}$ e $2^{\circ}$ graus, e das outras providências. Brasília. 1971. Disponível em: http://www2.camara.leg.br/legin/fed/lei/1970-1979/lei5692-11-agosto-1971-357752-publicacaooriginal-1-pl.html Acesso em: 25 nov. 2020

BRASIL. Lei $n^{\circ} 7.044$, de 18 de Outubro de 1982. Altera dispositivos da Lei $n^{\circ} 5.692$, de 11 de agosto de 1971, referentes a profissionalização do ensino de $2^{\circ}$ grau. Disponível em:

https://www2.camara.leg.br/legin/fed/lei/1980-1987/lei-7044-18-outubro-1982-357120-publicacaooriginal-1pl.html Acesso em: 25 nov. 2020

BRASIL. Ministério da Educação, Conselho Nacional de Educação. Resolução CNE/CP 9, de 8 de maio de 2001. Institui Diretrizes Curriculares Nacionais para a Formação de Professores da Educação Básica, em nível superior, Curso de Licenciatura, de graduação plena. Brasília, 2001. Disponível em http://portal.mec.gov.br/cne/arquivos/pdf/009.pdf Acesso em: 25 nov. 2020

BRASIL. Diretrizes Curriculares Nacionais para a Educação Básica (DCN), Brasília, 2013. Disponível em: http://portal.mec.gov.br/index.php?option=com_docman\&view=download\&alias=15548-d-c-n-educacaobasica-nova-pdf\&ltemid=30192. Acesso em: 25 nov. 2020

BRASIL. Resolução CNE/CP 2, de $1^{\circ}$ de julho de 2015. Brasília. 2015. Institui Diretrizes Curriculares Nacionais para a Formação Inicial em Nível Superior e para a formação continuada. Disponível em:

http://pronacampo.mec.gov.br/images/pdf/res_cne_cp_02_03072015.pdf

BRASIL. MINISTÉRIO DA EDUCAÇÃO. MEC. Censo da Educação Superior: notas estatísticas, Brasília, 2016.

Disponível em:

http://download.inep.gov.br/educacao_superior/censo_superior/documentos/2016/notas_sobre_o_censo_da_ educacao_superior_2016.pdf. Acesso em: 25 nov. 2020

CESÁRIO, M; LUGLE, A. M. C; CARVALHO, A. M. F. T; CZERNISZ, E. C. S; FÁVARO, M. R. G. Concepção de Estágio dos Cursos de Licenciaturas da UEL. LIMA, A. M. S. (org.) Os estágios nas licenciaturas da UEL. Londrina: UEL. 2013.

FRANÇA, S. S. A. Políticas para formação de professores: reflexões sobre o estágio supervisionado - do legal ao real. 2012. 135f. Dissertação (Mestrado em Educação) - Universidade Estadual Paulista, UNESP,

Presidente Prudente, SP

FONTANA, R. A. C. Estágio: do labirinto aos frágeis Fios de Ariadne. In: A. V. GONÇALVES, A. S. PINHEIRO, \& M. A. FERRO, (orgs.) Estágio Supervisionado e Práticas Educativas: Diálogos interdisciplinares. Dourados, MS: Editora UEMS, 2011

GAMBOA, S. S. Pesquisa em Educação: métodos e epistemologias. Chapecó: Argos, 2012.

GIL, A. C. Como elaborar projetos de pesquisa. São Paulo: Atlas, 2002.

KONDER, L. O futuro da filosofia da práxis: o pensamento de Marx no século XII. Rio de Janeiro: Paz e Terra, 1992.

KOSIK, K. Dialética do concreto. Rio de Janeiro: Paz e Terra, 1976.

PIMENTA, S. G. \& LIMA, M. S. L. Estágio e docência: diferentes concepções. Revista Poiesis. v. 3, n. 3 e 4 , p.5-24.2006 Disponível em: http://www.revistas.ufg.br/index.php/poesis/article/view/10542/7012 Acesso em: 25 nov. 2020

RODRIGUES, M. A N. A (re)configurações sobre o trabalho docente em relatórios de estágio. 2011. $167 f$. Tese (Doutorado em Linguística) - Universidade Federal da Paraíba, João Pessoa.

SANTANA, A. C. M. \& INFORSATO, E. C. O Estágio Supervisionado na formação Docente. Caminhos da Educação. v.3, n.1, p. 1-25.2011 Recuperado em 08 dezembro 2015, de http://periodicos.franca.unesp.br/index.php/caminhos/article/view/290/384 Acesso em: 25 nov. 2020.

SILVA, W. R; PEREIRA, B. G. Estágio supervisionado como componente curricular catalisador de saberes na formação inicial do professor. Domínio de Linguagem, Uberlândia, v. 10, n. 1, p. 146-165, jan./mar. 2016. Disponível em: http://www.seer.ufu.br/index.php/dominiosdelinguagem/article/view/32164/18087 . Acesso em: 25 nov. 2020.

TÉO, C. E. (2012) Estágio curricular supervisionado como campo de pesquisa na formação inicial do professor de educação física da UEL. Dissertação de Mestrado, Universidade Estadual de Londrina, Londrina, PR, Brasil. Disponível em:

http://www.uel.br/pos/mestredu/images/stories/downloads/dissertacoes/2013/2013_-

TEO Carlos eduardo.pdf Acesso em: 25 nov. 2020

TERRIBILI FILHO, A. Ensino Superior Noturno no Brasil: Estudar para trabalhar ou trabalhar para estudar?. Pensamento e Realidade, São Paulo, v. 22, p. 43-65, 2008. Disponível em: https://revistas.pucsp.br/index.php/pensamentorealidade/article/view/8299/6172 . Acesso em: 25 nov. 2020 VASQUEZ, A. S. Filosofia da Práxis. Rio de Janeiro: Paz e Terra, 1977.

Recebido em 23-01-2021 Revisões requeridas em 15-04-2021 Aceito em 28-04-2021

Revista Trama | Volume 17 | Número 41 | Ano 2021 | p. 45-58 | e-ISSN 1981-4674 